\title{
Comparative outcomes between totally laparoscopic total gastrectomy with the modified overlap method for early gastric cancer and advanced gastric cancer: review of 149 consecutive
} cases

\author{
Minha Choi, Chang Suk Ko, Jeong Hwan Yook, Byung-Sik Kim, Beom Su Kim \\ Department of Surgery, Asan Medical Center, University of Ulsan College of Medicine, Seoul, Korea
}

Videosurgery Miniinv 2020; 15 (3): 437-445 DOI: https://doi.org/10.5114/wiitm.2020.96098

\begin{abstract}
Introduction: Totally laparoscopic total gastrectomy (TLTG) for advanced gastric cancer (AGC) has not been conclusively substantiated.

Aim: To evaluate TLTG treatment of AGC by comparing its effectiveness and surgical outcomes to those of TLTG treatment of early gastric cancer ( $E G C$ ).

Material and methods: We performed TLTG with the (modified) overlap method for 149 gastric cancer cases between March 2012 and December 2018. We evaluated clinicopathologic characteristics, complications (including esophagojejunostomy site complications), and surgical outcomes. We also evaluated these variables in terms of their associations with EGC and AGC.

Results: Ninety-two males and 57 females, with a mean age of 60.7 years, were included. The mean operation time was 147.7 min. The mean number of harvested lymph nodes was 39.6. Thirteen (8.7\%) patients experienced early complications, and $6(4.0 \%)$ experienced late complications (Clavien-Dindo classification $\geq I I I)$. Eight (5.4\%) patients underwent reoperation, and $8(5.4 \%)$ were readmitted due to complications. There were no statistically significant differences in operation time, hospital stay, or surgical mortality between EGC and AGC. However, there were significant differences in early complications, late complications, rate of reoperation, and rate of readmission between EGC and AGC.

Conclusions: Although it has some limitations, TLTG with the (modified) overlap method for AGC treatment is feasible, safe, and associated with favorable outcomes.
\end{abstract}

Key words: gastric cancer, totally laparoscopic total gastrectomy, overlap method.

\section{Introduction}

Laparoscopic distal gastrectomy (LDG) is an established treatment modality for early gastric cancer (EGC). Many studies, including prospective randomized clinical trials (RCTs), have proven the benefits of LDG for EGC, including low blood loss, low postoperative pain, early recovery and return to work, and earlier discharge from hospital [1-5]. Several retrospective studies have reported that laparoscopy-assisted total gastrectomy (LATG) is a feasible and safe procedure for gastric cancer with the following benefits: less blood loss, earlier postoperative recovery, reduced postoperative complications, and similar lymph node harvesting capacity, compared with open total gastrectomy (OTG) [6-11]. As new

\section{Address for correspondence}

Beom Su Kim MD, PhD, Department of Surgery, University of Ulsan College of Medicine, 88 Olympic-ro, 43-gil, Songpa-Gu, Seoul 05505,

Korea, phone: +82 23010 3932, fax: +82 2474 9027, e-mail: bskim0251@naver.com 
techniques for intracorporeal esophagojejunostomy (EJ) have been introduced, totally laparoscopic total gastrectomy (TLTG) has become a widely accepted treatment for cancer of the upper stomach [12-19]. However, laparoscopic total gastrectomy (LTG) has not been supported by randomized control trials, and OTG is still the standard for advanced gastric cancer (AGC) of the upper stomach.

\section{Aim}

This study aimed to confirm the safety and feasibility of TLTG using the modified overlap method for the treatment of AGC by comparing it with TLTG for EGC.

\section{Material and methods}

We retrospectively collected and analyzed medical records' data for 149 patients who underwent curative TLTG with the modified overlap method for gastric cancer treatment between March 2012 and December 2018. All procedures were TLTGs with overlap EJ. We evaluated TNM stages using the seventh edition of the American Joint Committee on Cancer (AJCC) guidelines. Pain was measured using a visual analog score (VAS). We evaluated early complications ( $\leq 30$ days after surgery) and late complications ( $>30$ days after surgery). We also evaluated the methods for managing complications, reoperations, and readmissions. Complications were evaluated according to the Clavien-Dindo classification. Numerous clinicopathologic variables were evaluated. We also evaluated these variables in terms of their associations with EGC and AGC. Numerical data are described as means with standard deviations and were analyzed using Student's $t$-test. Cross-tabulation analysis was performed using the $\chi^{2}$ test. Survival analysis was performed using the Kaplan-Meier method and log-rank test. All statistical data were analyzed using SPSS Statistics for Windows, version 21.0 (IBM Corp., Armonk, NY, USA). P-values < 0.05 were considered statistically significant.

The protocols of this study were approved by the relevant institutional review board (2019-0702).

\section{Surgical anastomosis technique}

After TLTG, we performed intracorporeal EJ with the modified overlap method using a 45-mm linear stapler (Photo 1). During EJ, an angle of approximately $45^{\circ}$ from the esophagus was ensured (Photo $1 \mathrm{~A}$ ). After EJ formation, we closed the common opening transversely to prevent narrowing of the anastomosis using a 60-mm linear stapler with three stitches (Photo $1 \mathrm{~B}$ ). Photo $1 \mathrm{C}$ shows the final view after the completion of the modified overlap EJ. We then performed intracorporeal side-to-side jejunojejunostomy (J) using two 60-mm linear staplers approximately $40-45 \mathrm{~cm}$ from the EJ.

\section{Results}

\section{Clinicopathological characteristics of all patients}

The characteristics of all patients are summarized in Table I. A total of 149 patients who underwent TLTG with the modified overlap method were included, 92 (61.7\%) of whom were male, and 57 (38.3\%) of whom were female. The mean age of the patients was $60.7 \pm 11.5$ years. The mean body mass index (BMI) was $24.5 \pm 3.2 \mathrm{~kg} / \mathrm{m}^{2}$. Seventy-four (49.7\%) patients had comorbidities, and 31 (20.8\%) patients had a history of abdominal surgery ( 24 had minor surgery, and 7 had major surgery). Thirty (20.1\%) patients had an American Society of Anesthesiologists (ASA) score of 1,112 (75.2\%) had a score of 2, and $7(4.7 \%)$ had a score of 3 . Surgical outcomes and pathologic outcomes are summarized in Table II. The mean operation (procedure) time was $147.7 \pm 29.8$ $\mathrm{min}$. The mean time to first postoperative flatus was 3.7 days. Six (4.0\%) patients received perioperative transfusion. The mean peak pain score (VAS) after surgery was $5.0 \pm 1.8$. Patients received a mean of 9.7 postoperative analgesic doses before discharge, with a mean of 2.9 (mean) opioid doses. The mean postoperative hospital stay was 9.9 days. We harvested a mean of 39.6 lymph nodes intraoperatively. Regarding tumor stage, 107 (71.8\%) cases were diagnosed as AJCC stage I, 28 (18.8\%) as stage II, and $14(9.4 \%)$ as stage III. One (0.7\%) patient died of postoperative bleeding. Six (4.0\%) cases of tumor recurrence, and 15 (10.1\%) late postoperative deaths occurred. Figures 1 and 2 show the recurrence-free survival and overall survival rates.

\section{Postoperative complications}

Postoperative complications are shown in Table III. We evaluated early and late complications. A total of 32 (21.5\%) patients had early surgical complications, among whom 13 (8.7\%) had Clavien-Dindo $\geq$ III complications. The most common complication was ileus 

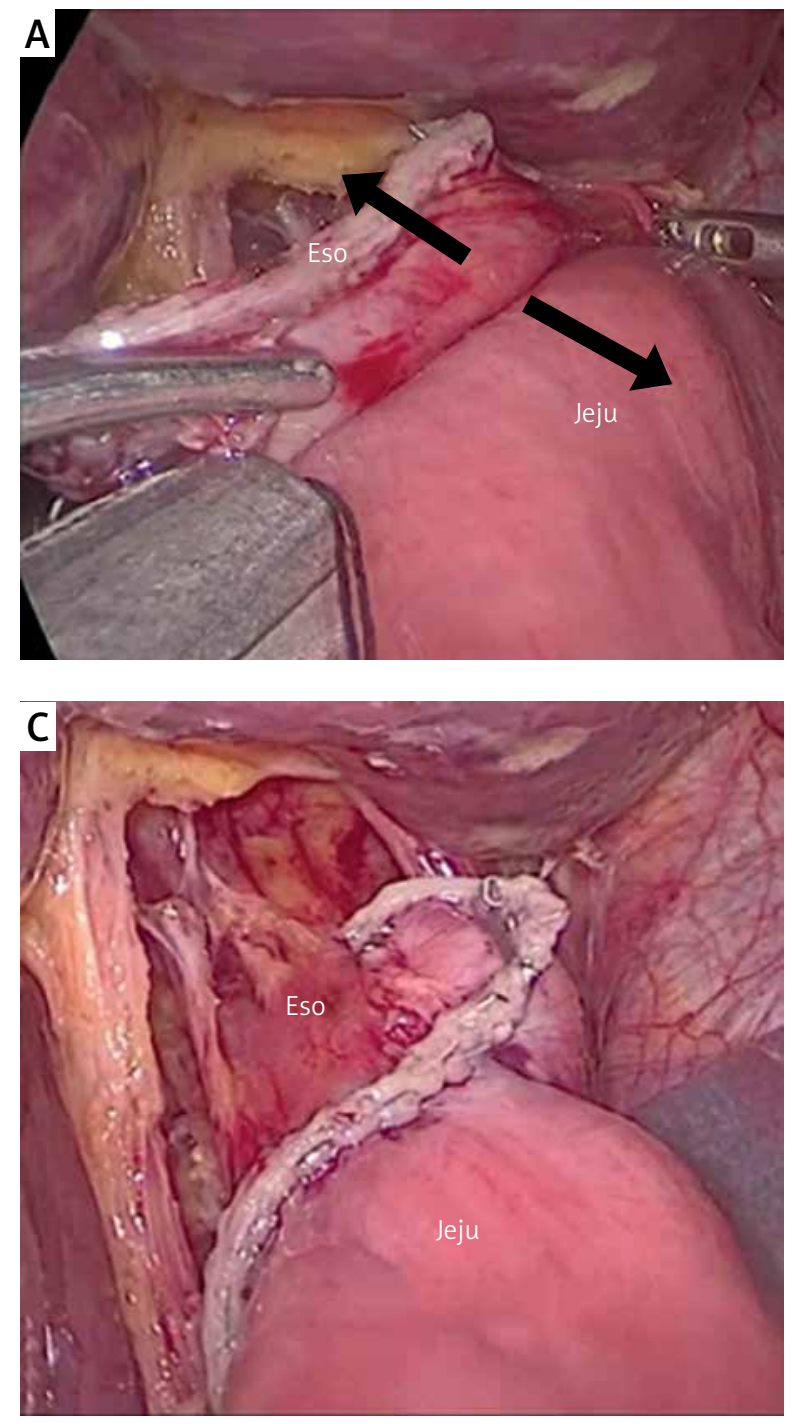

(early $8.1 \%$, late $4.0 \%$ ). Three (2.0\%) patients had EJ site complications, 2 (1.3\%) of which were EJ site leakages, with the other (0.7\%) being EJ site bleeding. However, EJ stenosis was not noted in any patient. Eight (6.0\%) patients had late surgical complications, among whom 6 (4.0\%) had Clavien-Dindo $\geq$ III complications. Among the complications, 24 (16.1\%) cases received conservative treatment, 7 cases received interventional treatment, and 8 (5.4\%) underwent reoperations. Eight (5.4\%) patients were readmitted after leaving the hospital.

\section{Clinical and surgical outcomes between EGC and AGC}

We evaluated outcomes according to their associations with EGC and AGC. The clinical characteris-

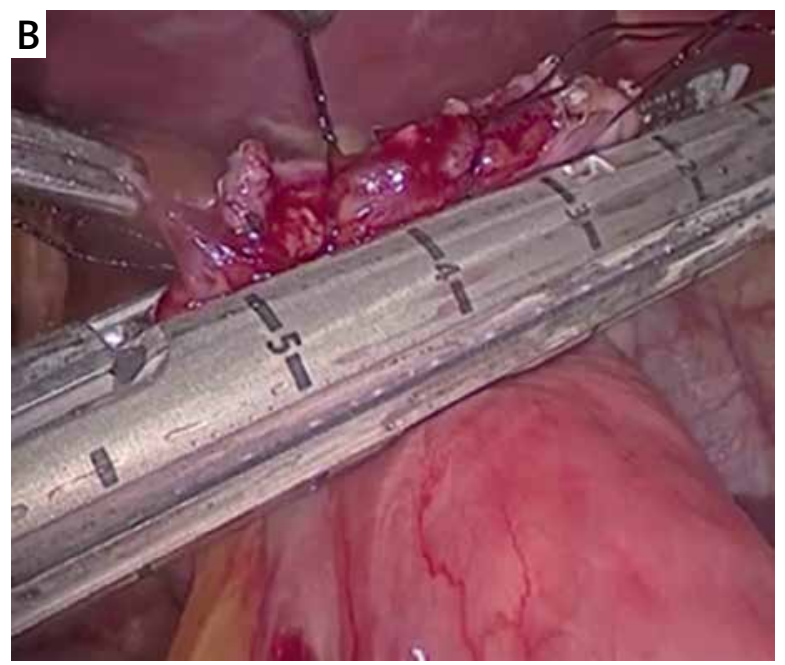

Photo 1. Photo of the modified overlap method. A - anastomosis, B - closure of the common hole, $\mathbf{C}$ - final view after anastomosis

Eso-esophagus, Jeju-jejunum.

tics of matched patients are summarized in Table IV. Between patients with EGC and AGC, there were no statistically significant differences in age, sex BMI, ASA score, comorbidity, or history of abdominal surgery $(p>0.05)$. The surgical outcomes are shown in Table V. Except for recurrence rate, there were no statistically significant differences in any of the investigated surgical outcomes between patients with EGC and those with AGC $(p>0.05)$. Table VI shows the surgical complications experienced by patients with EGC and AGC. There were no statistically significant differences in any of the surgical complications, including Clavien-Dindo classification, between patients with EGC and those with $\operatorname{AGC}(p>0.05)$. Additionally, there was no significant difference in terms of the management of complications between 
Table I. Clinical characteristics of all patients $(n=149)$

\begin{tabular}{|lc|}
\hline Characteristics & Results \\
\hline Age [years] & $60.7 \pm 11.5$ \\
\hline Sex: & $92(61.7)$ \\
\hline Male & $57(38.3)$ \\
\hline Female & $24.5 \pm 3.2$ \\
\hline BMI [kg/m²] & $30(20.1)$ \\
\hline ASA score: & $112(75.2)$ \\
\hline 1 & $7(4.7)$ \\
\hline 2 & $75(50.3)$ \\
\hline 3 & $74(49.7)$ \\
\hline Comorbidities: & $31(20.8)$ \\
\hline No & $24(16.1)$ \\
\hline Yes & $7(4.7)$ \\
\hline History of abdominal surgery: & \\
\hline \begin{tabular}{l} 
Minor surgery \\
\hline Major surgery
\end{tabular} \\
$\begin{array}{l}\text { Values are expressed as mean } \pm \text { standard deviation or number (\%). } \\
\text { BMI - body mass index. ASA - American Society of Anesthesiologists. }\end{array}$ \\
\hline
\end{tabular}

patients with EGC and those with AGC $(p>0.05)$. Finally, the rates of reoperation, readmission, and surgical mortality were similar between the EGC and $\operatorname{AGC}$ groups $(p>0.05)$.

\section{Discussion}

Recently, the incidence of gastric cancer of the upper stomach has increased around the world [20]. Unlike Korea and Japan, more than $80 \%$ of gastric cancer patients in most countries worldwide are diagnosed with AGC [21]. Therefore, LTG for AGC is a very important issue. Though LTG is less invasive, a highly complex technique is required for lymph node dissection because of the high risk of bleeding, technical difficulty of anastomosis, and narrow view $[8,22]$. While TLTG is widely accepted worldwide, three main issues should be overcome: safety, feasibility, and oncologic outcomes.

The safety and feasibility of LDG for early and advanced gastric cancer were confirmed by two large-scale RCTs in Korea and China [23, 24], and an RCT comparing TLTG with OTG is ongoing. Min et al. reported their 15-year experience of 1483 laparoscopic gastrectomies (including 432 LTGs) for advanced gastric cancer [25]. Grade $\geq$ III Clavien-Dindo
Table II. Surgical outcomes and pathologic results for all patients $(n=151)$

\begin{tabular}{|c|c|}
\hline Variable & Results \\
\hline Operative time (procedure) time (mean $\pm \mathrm{SD}$ ) & $147.7 \pm 29.8$ \\
\hline Time to first flatus [days] (mean \pm SD) & $3.7 \pm 0.9$ \\
\hline \multicolumn{2}{|l|}{ Transfusion, $n(\%)$ : } \\
\hline No & $143(96.0)$ \\
\hline Yes & $6(4.0)$ \\
\hline Peak pain score (VAS) & $5.0 \pm 1.8$ \\
\hline Administration of analgesics & $9.7 \pm 8.9$ \\
\hline Administration of opioid & $2.9 \pm 5.5$ \\
\hline Hospital stay after surgery [days] & $9.9 \pm 6.4$ \\
\hline Tumor size $[\mathrm{cm}]$ & $4.0 \pm 2.8$ \\
\hline Retrieved lymph nodes & $39.6 \pm 15.7$ \\
\hline \multicolumn{2}{|l|}{ T stage, $n(\%)$ : } \\
\hline $\mathrm{T} 1$ & $101(67.8)$ \\
\hline $\mathrm{T} 2$ & $11(7.4)$ \\
\hline T3 & $24(16.1)$ \\
\hline T4 & $13(8.7)$ \\
\hline \multicolumn{2}{|l|}{ N stage, $n(\%):$} \\
\hline NO & $116(77.9)$ \\
\hline N1 & $21(14.1)$ \\
\hline $\mathrm{N} 2$ & $7(4.7)$ \\
\hline N3 & $5(3.4)$ \\
\hline \multicolumn{2}{|l|}{ TNM stage, $n(\%)$ : } \\
\hline 1 & $107(71.8)$ \\
\hline 2 & $28(18.8)$ \\
\hline 3 & $14(9.4)$ \\
\hline 4 & 0 \\
\hline Surgical mortality, $n$ (\%) & $1(0.7)$ \\
\hline Recurrence, $n(\%)$ & $6(4.0)$ \\
\hline Death after surgery, $n(\%)$ & $15(10.1)$ \\
\hline
\end{tabular}

Values are expressed as mean \pm standard deviation or number (\%). VAS visual analog scale.

complications accounted for $4.9 \%$ of complications occurring within 30 postoperative days. Chen et al. reported a case-matched study dealing with TLTG versus OTG for 122 EGC patients and 126 AGC patients [26]. They showed that postoperative complications were experienced by 18 out of 124 patients who underwent TLTG and 22 out of 124 patients who underwent OTG; this difference 
A

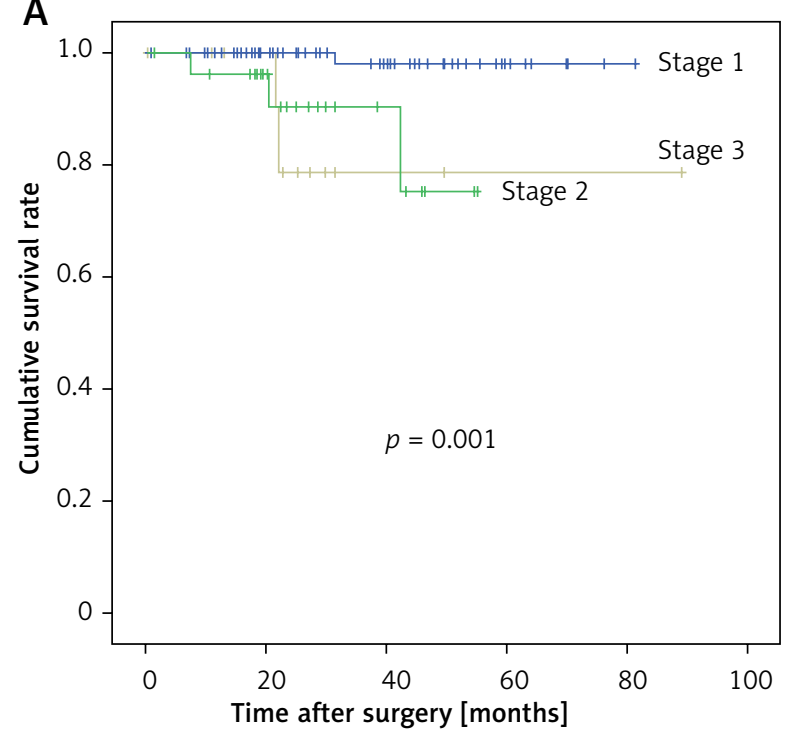

B

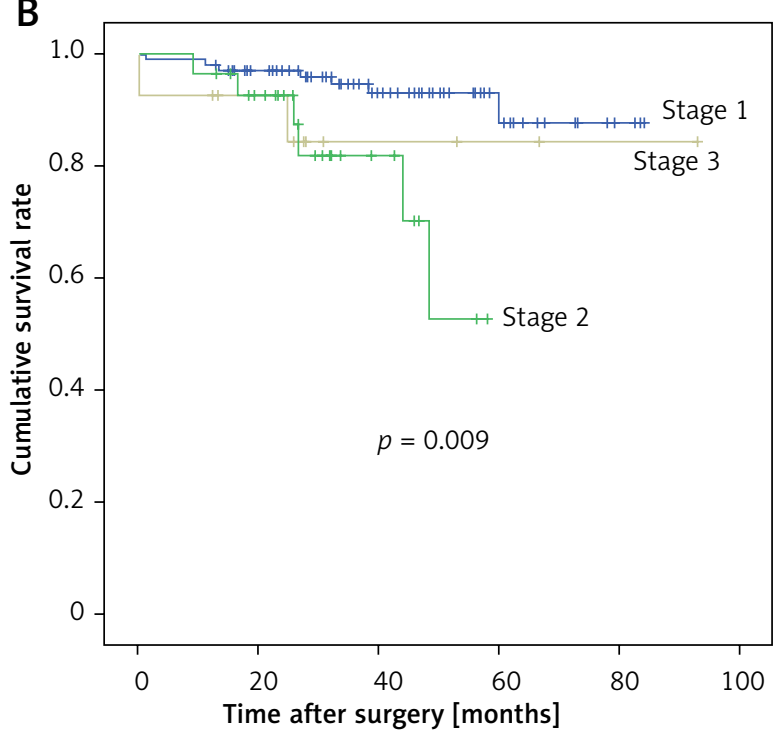

Figure 1. Survival curves according to stages: A - recurrence-free survival, B - overall survival

A

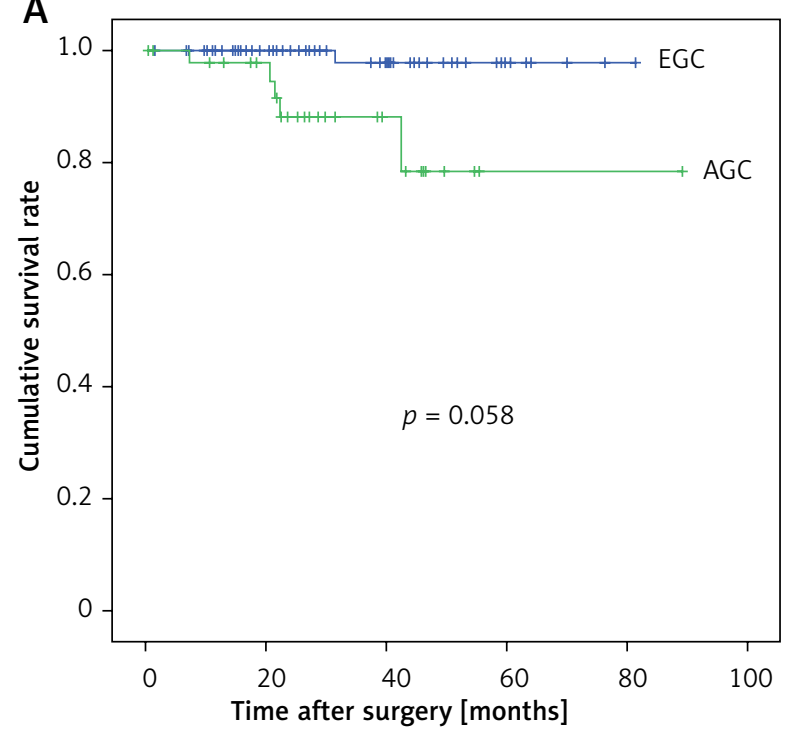

B

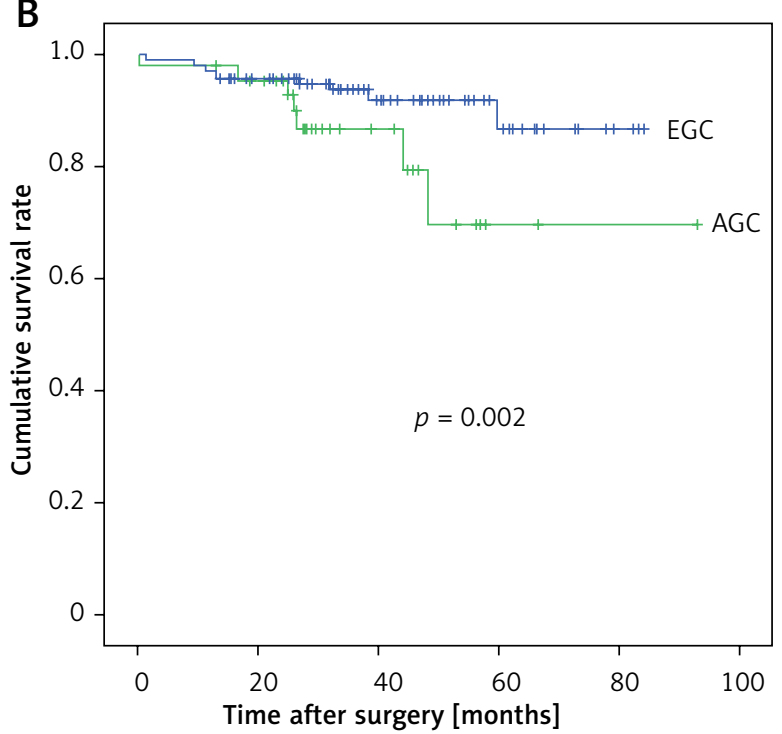

Figure 2. Survival curves between early gastric cancer and advanced gastric cancer: A - recurrence-free survival, B - overall survival

was not statistically significant (14.5\% vs. $17.7 \%)$. The anastomosis-related complications included three cases of anastomotic leakage at the EJ site and 2 cases of stricture in both groups, respectively. Recently, two RCTs investigating only TLTG (and not OTG) were reported $[27,28]$. The Chinese Laparoscopic Gastrointestinal Surgery Study (CLASS) Group reported the safety and feasibility of laparoscopic spleen-preserving No. 10 lymph node dissection for locally advanced upper-third gastric cancer
(CLASS 04) [28]. The investigators reported that $13.6 \%(33 / 242)$ of patients experienced complications within 30 postoperative days, including $0.6 \%$ $(1 / 242)$ who died and $3.3 \%(8 / 242)$ of patients who exhibited grade III or higher complications, according to the Clavien-Dindo classification; 2.9\% (7/242) of patients experienced anastomosis leakage. The Korean Laparoendoscopic Gastrointestinal Surgery Study (KLASS) group conducted a prospective multi-center trial of LTG for clinical stage I gastric 
Table III. Postoperative complications

\begin{tabular}{|c|c|c|c|}
\hline Variable & Early complications, $n$ (\%) & Late complications, $n(\%)$ & Total, $n(\%)$ \\
\hline Wound complications & $3(2.0)$ & 0 & $3(2.7)$ \\
\hline Fluid collection & $7(7.4)$ & $1(0.7)$ & $8(5.4)$ \\
\hline Bleeding & $1(0.7)$ & 0 & $1(2.0)$ \\
\hline EJ site leak/bleeding & $2(1.3) / 1(0.7)$ & 0 & $2(1.3) / 1(0.7)$ \\
\hline Duodenal stump leak & $3(2.0)$ & $1(0.7)$ & $4(2.7)$ \\
\hline Ileus & $12(8.1)$ & $6(4.0)$ & $18(12.1)$ \\
\hline Pulmonary complications & $2(1.3)$ & 0 & $2(1.3)$ \\
\hline Cholecystitis & $1(0.7)$ & 0 & $1(0.7)$ \\
\hline Total & $32(21.5)$ & $8(5.4)$ & $37^{\star}(24.8)$ \\
\hline \multicolumn{4}{|l|}{ Clavien-Dindo classification: } \\
\hline I & $6(4.0)$ & 0 & $6(4.0)$ \\
\hline ॥ & $14(9.4)$ & $3(2.0)$ & 17 (11.4) \\
\hline IIIa/IIIb & $6(4.0) / 4(2.7)$ & $1(0.7) / 4(2.7)$ & $7(4.7) / 8(5.4)$ \\
\hline $\mathrm{IVa} / \mathrm{b}$ & $0 / 1(0.7)$ & $0 / 0$ & 0/1(0.7) \\
\hline $\mathrm{V}$ & $1(0.7)$ & $1(0.7)$ & $1(0.7)$ \\
\hline \multicolumn{4}{|c|}{ Management for complications: } \\
\hline Conservative & $21(14.1)$ & $3(2.0)$ & $24(16.1)$ \\
\hline Intervention & $6(4.0)$ & $1(0.7)$ & $7(4.7)$ \\
\hline Reoperation & $5(3.4)$ & $4(2.7)$ & $8^{* \star}(5.4)$ \\
\hline Readmission & 0 & $8(5.4)$ & $8(5.4)$ \\
\hline Surgical mortality & $1(0.7)$ & 0 & $1(0.7)$ \\
\hline
\end{tabular}

cancer to determine the safety and feasibility of LTG [27]. The short-term results of the safety and feasibility of LTG (KLASS-03 trial, 179 patients) were reported [27]. The investigators reported that 33 (20.6\%) patients experienced complications within 30 postoperative days, including $1(0.6 \%)$ postoperative death, and 15 (9.4\%) patients exhibited grade III or higher complications, according to the Clavien-Dindo classification; 5 (3.2\%) patients experienced EJ complications. In our present study, among 107 patients with stage I cancer, 21 (21.5\%) experienced complications within 30 days without mortality, 9 (8.4\%) patients exhibited grade III or higher complications, according to the Clavien-Dindo classification, and only 1 (0.9\%) patient experienced EJ complications. Nakauchi et al. reported the results of 92 TLTGs for advanced gastric cancer (54 patients received neoadjuvant chemotherapy) [29]. They found that the incidence rates for early and late morbidities (Clavien-Dindo grade $\geq \mathrm{III}$ ) were
26.1 and $6.5 \%$, respectively, and that 18 (19.8\%) patients experienced EJ leakage. In the present study, we performed 48 TLTGs with the modified overlap method for advanced gastric cancer. Among 48 patients, 10 (20.8\%) experienced complications within 30 days, with 1 (2.1\%) death; 6 (5.9\%) patients exhibited grade III or higher complications according to the Clavien-Dindo classification; and 2 (4.2\%) patients experienced EJ complications.

Oncologic outcome is another important issue. Unfortunately, no RCTs have investigated oncologic outcomes of TLTG for AGC. Long-term outcomes of total gastrectomy were reported in 2015 [30]. The 5-year overall survival rate was $97 \%$ for stage IA, $74.4 \%$ for stage IB, 63\% for stage IIA, 53.2\% for stage IIB, 56.5\% for stage IIIA, $32.5 \%$ for stage IIIB, and $15.6 \%$ for stage IIIC. The 5-year overall survival was $88.3 \%$ for $\mathrm{T} 1 \mathrm{a}$, $92 \%$ for $\mathrm{T} 1 \mathrm{~b}, 63.3 \%$ for $\mathrm{T} 2,80 \%$ for $\mathrm{T} 3$, and $32.5 \%$ for T4a. Min et al. reported their 15-year experience of laparoscopic gastrectomy for AGC [25]. They report- 
Table IV. Clinical characteristics between early gastric cancer and advanced gastric cancer

\begin{tabular}{|c|c|c|c|}
\hline Variable & Early gastric cancer $(n=101)$ & Advanced gastric cancer $(n=48)$ & $P$-value \\
\hline Age [years] & $60.6 \pm 10.8$ & $60.9 \pm 12.9$ & 0.861 \\
\hline Sex: & & & 0.210 \\
\hline Male & $66(65.3)$ & $26(54.2)$ & \\
\hline Female & $35(34.7)$ & $22(45.8)$ & \\
\hline $\mathrm{BMI}\left[\mathrm{kg} / \mathrm{m}^{2}\right]$ & $24.7 \pm 3.2$ & $24.3 \pm 3.2$ & 0.460 \\
\hline ASA score: & & & 0.131 \\
\hline 1 & $24(23.8)$ & $6(12.5)$ & \\
\hline 2 & $71(70.3)$ & $41(85.4)$ & \\
\hline 3 & $6(5.9)$ & 192.1) & \\
\hline Comorbidity: & & & 0.296 \\
\hline No & $54(53.5)$ & $21(43.8)$ & \\
\hline Yes & $47(46.5)$ & $27(56.2)$ & \\
\hline History of abdominal surgery: & $20(19.8)$ & $11(22.9)$ & 0.670 \\
\hline Minor surgery & $16(15.8)$ & $8(16.7)$ & 1.000 \\
\hline Major surgery & $4(4.0)$ & $3(6.2)$ & 0.681 \\
\hline
\end{tabular}

Values are expressed as mean \pm standard deviation or number (\%). BMI - body mass index, ASA - American Society of Anesthesiologists.

Table V. Surgical outcomes of patients with early gastric cancer and advanced gastric cancer

\begin{tabular}{|lccc|}
\hline Variable & Early gastric cancer $(n=101)$ & Advanced gastric cancer $(n=48)$ & $P$-value \\
\hline Operation (procedure) time & $148.7 \pm 31.8$ & $145.5 \pm 25.4$ & 0.542 \\
\hline Perioperative transfusion & $3(3.0)$ & $3(6.2)$ & 0.387 \\
\hline Time to first flatus [days] & $3.8 \pm 0.9$ & $3.6 \pm 7.1$ & 0.126 \\
\hline Peak pain score (VAS) & $4.9 \pm 1.7$ & $5.3 \pm 1.9$ & 0.237 \\
\hline Administration of analgesics & $9.7 \pm 9.0$ & $9.6 \pm 9.0$ & 0.910 \\
\hline Administration of opioid & $2.9 \pm 6.2$ & $2.7 \pm 3.9$ & 0.764 \\
\hline Retrieved lymph nodes & $38.6 \pm 15.2$ & $41.7 \pm 15.2$ & 0.270 \\
\hline Hospital stay [days] & $10.0 \pm 6.0$ & $9.9 \pm 7.3$ & 0.876 \\
\hline Mortality & 0 & $1(2.1)$ & 0.322 \\
\hline Recurrence & $1(1.0)$ & $5(10.4)$ & 0.002 \\
\hline
\end{tabular}

Values are expressed as mean \pm standard deviation or number (\%). VAS - visual analog scale.

ed 5-year overall survival rates, stratified by stage, as follows: stage IB $88.9 \%$, stage IIA $88.7 \%$, stage IIB $84.2 \%$, stage IIIA $71.7 \%$, stage IIIB $56.8 \%$, stage IIIC $45.4 \%$, and stage IV $25 \%$. The overall recurrence rate was $14.4 \%$, which included local recurrence (1.1\%) and distant metastases (13.3\%). A 2016 report [29] summarized short- and long-term outcomes of TLTG for AGC [29]. The authors reported that the 3-year overall survival rates for pl, pll, and plll were $100.0 \%$, $93.8 \%, 72.7 \%$, and $58.7 \%$, respectively (Figure 2), and the 3-year recurrence-free survival rates were $100.0 \%, 100.0 \%, 66.7 \%$, and $39.0 \%$, respectively. The Japanese Gastric Cancer Association (JGCA) annual report includes 208 participating hospitals and 53 retrospectively documented items, including the surgical procedures, pathological diagnosis, and survival outcomes of 13,626 patients with primary gastric cancer. In 2002, the 5-year overall survival rates of the patients, stratified by the JGCA staging system, were $92.2 \%$ for stage IA, $85.3 \%$ for stage IB, $72.1 \%$ for 
Table VI. Postoperative complications of patients with early gastric cancer and advanced gastric cancer

\begin{tabular}{|c|c|c|c|}
\hline Variable & $\begin{array}{l}\text { Early gastric cancer } \\
\qquad \begin{array}{c}(N=101) \\
n(\%)\end{array}\end{array}$ & $\begin{array}{l}\text { Advanced gastric cancer } \\
\qquad(N=48) \\
n(\%)\end{array}$ & $P$-value \\
\hline Wound complication & $1(0.9)$ & $2(4.2)$ & 0.234 \\
\hline Fluid collection & $7(6.9)$ & $1(2.1)$ & 0.220 \\
\hline Bleeding & $1(0.9)$ & 0 & 1.000 \\
\hline EJ site complication & $1(0.9)$ & $2(4.2)$ & 0.234 \\
\hline Duodenal stump leak & $3(2.9)$ & 0 & 0.551 \\
\hline Ileus & $12(9.1)$ & $4(8.3)$ & 0.513 \\
\hline Pulmonary complications & $1(0.9)$ & $1(2.1)$ & 0.542 \\
\hline Cholecystitis & 0 & $1(2.1)$ & 0.322 \\
\hline Total & $26(25.7)$ & $11(22.9)$ & 0.709 \\
\hline Early complication & $22(21.8)$ & $10(20.8)$ & 0.895 \\
\hline Late complication & $7(6.9)$ & $1(2.1)$ & 0.220 \\
\hline Clavien-Dindo classification: & & & 0.904 \\
\hline$<3$ & $16(15.8)$ & $7(14.6)$ & \\
\hline$\geq 3$ & $10(9.9)$ & $4(8.3)$ & \\
\hline Management for complication: & $n=26$ & $n=11$ & 0.463 \\
\hline Conservative & $16(61.5)$ & $8(72.7)$ & \\
\hline Intervention & $3(11.5)$ & $2(18.2)$ & \\
\hline Reoperation & $7(27.0)$ & $1(9.1)$ & \\
\hline Readmission & $7(6.9)$ & $1(2.1)$ & 0.220 \\
\hline Surgical mortality & 0 & $1(2.1)$ & 0.322 \\
\hline
\end{tabular}

stage II, 52.8\% for stage IIIA, 31.0\% for stage IIIB, and $14.9 \%$ for stage IV. Additionally, the 3-year survival rates were $94.9 \%$ for $\mathrm{pT} 1,87.2 \%$ for $\mathrm{pT} 2,67.9 \%$ for pT3, and $40.3 \%$ for pT4a. In our study, the 3-year survival rates were $93.5 \%$ for pT1, 100\% for pT2, 93.3\% for pT3, and $63.9 \%$ for pT4a. Also, the 3-year and 5 -year overall survival rates were $96.1 \%$ and $93.0 \%$ for stage I, $82.1 \%$ and $52.8 \%$ for stage II, and $84.4 \%$ and $84.4 \%$ for stage III, respectively.

This study had some limitations. First, it was a retrospective study performed at a single institution. Second, the number of enrolled patients was relatively small. Third, we did not assess the longterm oncologic outcomes.

\section{Conclusions}

Despite some limitations, TLTG with the modified overlap method is a feasible and safe procedure associated with favorable surgical outcomes for the treatment of EGC as well as for AGC.

\section{Conflict of interest}

The authors declare no conflict of interest.

\section{References}

1. Adachi Y, Shiraishi N, Shiromizu A, et al. Laparoscopy-assisted billroth i gastrectomy compared with conventional open gastrectomy. Arch Surg 2000; 135: 806-10.

2. Kim HH, Hyung WJ, Cho GS, et al. Morbidity and mortality of laparoscopic gastrectomy versus open gastrectomy for gastric cancer: an interim report - a phase iii multicenter, prospective, randomized trial (KLASS Trial). Ann Surg 2010; 251: 417-20.

3. Lee SE, Kim YW, Lee JH, et al. Developing an institutional protocol guideline for laparoscopy-assisted distal gastrectomy. Ann Surg Oncol 2009; 16: 2231-6.

4. Ryu KW, Kim YW, Lee JH, et al. Surgical complications and the risk factors of laparoscopy-assisted distal gastrectomy in early gastric cancer. Ann Surg Oncol 2008; 15: 1625-31. 
5. Viñuela EF, Gonen M, Brennan MF, et al. Laparoscopic versus open distal gastrectomy for gastric cancer: a meta-analysis of randomized controlled trials and high-quality nonrandomized studies. Ann Surg 2012; 255: 446-56.

6. Asao T, Hosouchi Y, Nakabayashi T, et al. Laparoscopically assisted total or distal gastrectomy with lymph node dissection for early gastric cancer. Br J Surg 2001; 88: 128-32.

7. Azagra JS, Goergen M, De Simone P, Ibanez-Aguirre J. Minimally invasive surgery for gastric cancer. Surg Endosc 1999; 13: 351-7.

8. Usui S, Yoshida T, Ito K, et al. Laparoscopy-assisted total gastrectomy for early gastric cancer: comparison with conventional open total gastrectomy. Surg Laparosc Endosc Percutan Tech 2005; 15: 309-14.

9. Uyama I, Sugioka A, Fujita J, et al. Laparoscopic total gastrectomy with distal pancreatosplenectomy and D2 lymphadenectomy for advanced gastric cancer. Gastric Cancer 1999; 2: 230-4.

10. Wada N, Kurokawa Y, Takiguchi S, et al. Feasibility of laparoscopy-assisted total gastrectomy in patients with clinical stage I gastric cancer. Gastric Cancer 2014; 17: 137-40.

11. Mochiki E, Toyomasu Y, Ogata K, et al. Laparoscopically assisted total gastrectomy with lymph node dissection for upper and middle gastric cancer. Surg Endosc 2008; 22: 1997-2002.

12. Hara T, Fujiwara Y, Sugimura K, et al. Comparison of early clinical outcomes between laparoscopic total gastrectomy and open total gastrectomy for early-stage gastric cancer. Gan to Kagaku Ryoho 2014; 41: 1476-8.

13. Jeong O, Jung MR, Kim GY, et al. Comparison of short-term surgical outcomes between laparoscopic and open total gastrectomy for gastric carcinoma: case-control study using propensity score matching method. J Am Coll Surg 2013; 216: 184-91.

14. Kang SH, Cho YS, Min SH, et al. Intracorporeal esophagojejunostomy using a circular or a linear stapler in totally laparoscopic total gastrectomy: a propensity-matched analysis. J Gastric Cancer 2019; 19: 193-201.

15. Inaba K, Satoh S, Ishida Y, et al. Overlap method: novel intracorporeal esophagojejunostomy after laparoscopic total gastrectomy. J Am Coll Surg 2010; 211: e25-9.

16. Jeong O, Park YK. Intracorporeal circular stapling esophagojejunostomy using the transorally inserted anvil (OrVil) after laparoscopic total gastrectomy. Surg Endosc 2009; 23: 2624-30.

17. Kinoshita T, Oshiro T, Ito K, et al. Intracorporeal circular-stapled esophagojejunostomy using hand-sewn purse-string suture after laparoscopic total gastrectomy. Surg Endosc 2010; 24: 2908-12.

18. Okabe H, Obama K, Tanaka E, et al. Intracorporeal esophagojejunal anastomosis after laparoscopic total gastrectomy for patients with gastric cancer. Surg Endosc 2009; 23: 2167-71.

19. Usui S, Nagai K, Hiranuma S, et al. Laparoscopy-assisted esophagoenteral anastomosis using endoscopic purse-string suture instrument "Endo-PSI (II)" and circular stapler. Gastric Cancer 2008; 11: 233-7.

20. Kubo A, Corley DA. Marked regional variation in adenocarcinomas of the esophagus and the gastric cardia in the United States. Cancer 2002; 95: 2096-102.

21. Chen QY, Lin GT, Zhong Q, et al. Laparoscopic total gastrectomy for upper-middle advanced gastric cancer: analysis based on lymph node noncompliance. Gastric Cancer 2020; 23: 184-94.
22. Eom BW, Kim YW, Lee SE, et al. Survival and surgical outcomes after laparoscopy-assisted total gastrectomy for gastric cancer: case-control study. Surg Endosc 2012; 26: 3273-81.

23. Lee HJ, Hyung WJ, Yang HK, et al. Short-term outcomes of a multicenter randomized controlled trial comparing laparoscopic distal gastrectomy with D2 lymphadenectomy to open distal gastrectomy for locally advanced gastric cancer (KLASS02-RCT). Ann Surg 2019; 270: 983-91.

24. Yu J, Huang C, Sun Y, et al. Effect of laparoscopic vs open distal gastrectomy on 3-year disease-free survival in patients with locally advanced gastric cancer: the CLASS-01 randomized clinical trial. JAMA 2019; 321: 1983-92.

25. Min SH, Won Y, Kim G, et al. 15-year experience of laparoscopic gastrectomy in advanced gastric cancer: analysis on shortterm and long-term oncologic outcome. Surg Endosc 2019 doi: 10.1007/s00464-019-07292-x.

26. Chen K, Pan Y, Zhai ST, et al. Totally laparoscopic versus open total gastrectomy for gastric cancer: a case-matched study about short-term outcomes. Medicine 2017; 96: e8061.

27. Hyung WJ, Yang HK, Han SU, et al. A feasibility study of laparoscopic total gastrectomy for clinical stage I gastric cancer: a prospective multi-center phase II clinical trial, KLASS 03. Gastric Cancer 2019; 22: 214-22.

28. Zheng CH, Xu YC, Zhao G, et al. Safety and feasibility of laparoscopic spleen-preserving No. 10 lymph node dissection for locally advanced upper third gastric cancer: a prospective, multicenter clinical trial. Surg Endosc 2019 doi: 10.1007/s00464019-07306-8.

29. Nakauchi M, Suda K, Kadoya S, et al. Technical aspects and short- and long-term outcomes of totally laparoscopic total gastrectomy for advanced gastric cancer: a single-institution retrospective study. Surg Endosc 2016; 30: 4632-9.

30. da Costa WL Jr, Coimbra FJ, Ribeiro HS, et al. Total gastrectomy for gastric cancer: an analysis of postoperative and long-term outcomes through time: results of 413 consecutive cases in a single cancer center. Ann Surg Oncol 2015; 22: 750-7.

Received: 22.04.2020, accepted: 25.05.2020. 